\title{
Perception and preferences of the doctors from the Health Centers towards the use of antibiotics in Prishtina, Kosovo
}

\author{
Rudina Degjoni \\ Health Insurance Fund of Albania, Tirane, (Albania)
}

Leunora Brika Haxhiu

Agency for medical products and equipment, Prishtine, (Kosovo)

Rabishe Kurti Jaha

Owner of OJQF in Prishtine, (Kosovo), Simon R. P. Clarke, Thomas A. O'Donoghue, "School-Level Leadership in Post- Conflict Societies", 2013, Annual Report of Ministry of Health of Kosovo, (2015) "The Social Statistics" pg 42

\begin{abstract}
Background: Resistance to antibiotics is a global public health problem with economic, social and political implications, especially in underdeveloped countries. Over the last few years, this challenge has been of particular importance at the global level seriously endangering the effective treatment of many diseases. Purpose: The purpose of this study is to assess the level of use of antibiotics and practices followed by Pristina primary doctors in Kosovo and to educate and educate as many as possible the population of Pristina regarding the use of antibiotics in order to ensure the quality of their lives. Method: A survey was conducted with a random sampling, attended by about 120 doctors of KPSH to indicate whether they have antibiotics with whom they are familiar, as well as antibiotic access and preference, which is the same regardless of the type of specialization staff at the KPSH. Participants were recruited into one of the 12 Main Family Medicine Centers (KPSH) in Prishtina for the period June - July - August 2017. Results: Of the 120 doctors surveyed at KPSH, on the question of whether you have antibiotics with whom you are familiar with, more than half (55\%) do not have any favorite antibiotics, while $40 \%$ of them have some antibiotics with whom they are familiar. Though $6(8.1 \%)$ of family doctors have reported that they are familiar with many of the antibiotics, there is no significant difference between Chi-square $=4.76$; Df $=4 ; p=0.313$ after testing. About a quarter of the respondents describe antibiotics without antibiograms, and over half of them sometimes and only $10.8 \%$ do not prescribe antibiotics without antibiograms, regardless of the type of specialization of staff at SPC. Patient advise on side effects has been performed by most doctors of SCC and only 5 doctors or $4.2 \%$ do not give advice to their patients for side effects, but without significant difference depending on the type of specialization. Over $80 \%$ of respondents in their daily practice have encountered a known case of resistance to any antibiotic, but without significant difference depending on the type of specialization
\end{abstract}

Keywords: Pristina, use of antibiotics, primary health care, doctor, assessment of knowledge, attitudes, practices of Kosovar doctors.

\section{Introduction}

The doctor's antibiotic prescriptions are often the central part of the problem; thus, analyzing the reasons behind the antibiotic prescription from the doctors remains essential to understand the excessive use of this drug worldwide. Since Kosovo has been our targeted country to be evaluated regarding the implications of antibiotic use, a historical description will clarify the reasons behind antibiotic use: Kosovo is a new country located in the southeastern part of Europe in the Balkan region with a surface of 10,908 km2 1 . Preliminary results from the 2011 general census report that in the Republic of Kosovo there are 1,733,842 inhabitants excluding the population from the northern part of Kosovo. Kosovo has an

1 Simon R. P. Clarke, Thomas A. O'Donoghue, "School-Level Leadership in Post- Conflict Societies", 2013 
interesting and complex history. Health care in Kosovo has undergone important reforms in the last decade, but still faces major difficulties and obstacles, one being the lack of political engagement and scarce budgetary resources. The Kosovo health system is based on equality and social justice, consisting of: the primary health care centers located at the municipal level, secondary health facilities at the regional level (hospitals), and a single tertiary health care center ${ }^{1}$.

There is no health insurance system in Kosovo, which is a major obstacle to improving the healthcare sector. The budget for health care system in Kosovo for 2015 was only 160 million euro (80 euro per capita), the budget divided for the pharmaceutical sector was only 19.8 million euro. For 2016, the budget was worth EUR 100 million more than the 2015 budget. For 2017, the budget was EUR 2 billion, which showed a significant jump compared to 2016, and much larger difference compared to 2014 and 2015 budget. This budget increase goes mainly in capital investment, and not for coherent spending. Compared to 2016 , capital investments increased to $51 \%$, while current expenditures increased only by $5 \%$ more than in 2016.

For 2018, the health budget is planned to be 1 billion and 829 million euro, while spending will reach the figure of 2 billion and 82 million euro ${ }^{2}$. In Kosovo, since the post-war period of primary health care, twenty (20) therapeutic standard guidelines have been developed and 16 standard protocols for diagnosis and therapy have been completed but have not yet been put into use.

Kosovo ranks at a high level of antibiotic consumption in Europe, at about 26.3 (defined daily doses per 1000 inhabitants / day). Various publications in the academia have reflected upon the importance of antibiotic usage and their potential drawbacks. In Kosovo these researches are still in their initial stages.

Therefore, the purpose of this study is to assess the knowledge, attitudes and practices of Kosova doctors in the use of antibiotics ${ }^{3}$. This study also aims to raise awareness among doctors about the importance of using antibiotics, identify quality improvement objectives, and deliver findings found to competent antibiotic prevention authorities.

\section{The First Chapter}

\section{Primary Health Care (PHC) in Kosovo}

Primary Health Care has been presented in various forms since $1961^{4}$, and it presents essential health care which is offered through family medicine teams. Family Medicine is the essential form of offering extensive health service for individuals and their families in Primary Health Care. Primary Health Care in Kosovo is provided through municipalities, and Kosovo consists of 35 municipalities where these PHC facilities, respectively where the main Family Medicine Centers are located. In the Republic of Kosovo, The Municipal Department of Health and Social Welfare is in charge of implementing the concept of family medicine within the Primary Health Care. The Municipal Department of Health and Welfare monitors the health state of the citizens that come from their territories. Municipalities, in offering PHC, implement with priority, the preventive measures of health care. Primary Health Care is implemented by the family medicine team which consists of health workers such as the Doctor of Medicine, the Doctor of Stomatology, the Medical Specialist-New Family), the Master of Pharmacy, Pediatrician, Gynecologist Obstetrician, the Clinical Biochemistry Specialist, Nurses, Midwives, the Physiotherapist, and Medical technics. Primary Health Care includes services of health promotions, information, communication, education, progress, prevention, treatment, recovery and rehabilitation that have to do with illnesses, disorders and injuries (the health of children, adolescents, reproductive health, adult care, elderly care and palliative care. It also includes services of immunization, vaccination, determination of initial diagnosis, and elementary health care including minimal surgical interventions, promoting oral health and essential stomatology care, emergent care services, ante/peri care services, postnatal services, rehabilitation, the dispersal of medications from the essential list, and also providing qualitative water and food.

\section{Second Chapter}

\footnotetext{
${ }^{1}$ Annual Report of Ministry of Health of Kosovo, (2015) "The Social Statistics" pg 42

2 The Ministry of Health "The Health budget 2018"

${ }^{3}$ M.Berisha, D. Zajmi etc "Public knowledge, attitudes and practices regarding antibiotic use in Kosovo" (2017)

4 The Ministry of Health of Kosovo, "The Sectorial Strategy of Health Care in Kosovo 2010-2014" (2009) 


\section{Characteristics of the descriptive doctor at Primary Health Center, Kosovo}

The prescription of therapeutic use of antibiotics ${ }^{1}$ in a Primary Health Center in Kosovo is characterized from the level of specialization, university program or postgraduate studies. All of these elements play a major role in determining antibiotic prescription. From the users' perspective, the use of antibiotics is strongly dependent on socio-demographic parameters, and the perception of the user towards the drug and its characteristics. Moreover, the antibiotic usage has been analyzed due to the consequences they might have on health, unwanted effects, probable therapeutic effect or economic impact.

Medical prescription from doctors should always bear in mind that antimicrobial resistance is one of the most serious health threats to the patient's life. Although doctors have referred that bacterial infections are already very common, there are several pathogens that are more resistant to the types or classes of antibiotics used to treat all bacterial infections. Loss of antibiotic effect would damage the patient's ability to fight infectious diseases and could also affect the management of common infectious complications in needy patients through chemotherapy for cancer, dialysis for renal resuscitation, and surgery, particularly organ transplants, for which the ability to treat secondary infections is crucial ${ }^{2}$ (Frieden, 2013). The causes of resistance are: increased use of antibiotics, unreasonable use, taking antibiotics without doctor's prescription, lack of control of hospital infections, increasing the age of the population or mass movement of people from country to country. Excessive use of antibiotics is only fought if antibiotics are not taken without the prescription of the doctor, or if the use of antibiotics is coordinated by the prescription of the doctor of the Primary Health Center. Furthermore, the antibiotic ${ }^{3}$ should be given to the patient according to the schedule, and its use should be made according to medical advice by the doctor and pharmacist of the municipality, to avoid the use of antibiotics left over from the previous treatment, etc.

\section{Third Chapter}

\section{Research Methodology}

120 doctors of the Primary Health Care (PHC) in Kosovo 4 were surveyed through random sampling to evaluate the level of information regarding the variety of antibiotics in the market and to which of them the doctors are familiar; moreover, the survey analyzed how the doctors prescribed the usage of antibiotics and if there is any sort of connection between prescription and the doctor antibiotic preferences due to the field of expertise in Primary Health Care in Kosovo. The conduction of survey took place during the June-July-August 2017; whereas the surveyed doctors were randomly ${ }^{5}$ selected in 12 Family Medicine Center. The surveyed doctors were randomly selected and their response was voluntary. The calculations of the sample size were performed under the 'RAOSOFT' program which worked under a margin of error of $5 \%$, a confidence level of $95 \%$, and a $50 \%$ distribution of response. Since the study was designed to represent the situation across the country, we had to increase the sample reliability and sampling coverage through doubling the sample size. Among the participants in the survey, all of them were taken in 12 Family Medicine Centers in Prishtina. Ethical Approval for the survey participants is taken by the Board of Professional Ethics Oversight in the Ministry of Health of Kosovo. The study was conducted through a face-to-face interview based on a questionnaire that contained two open and closed questions. The first part of the questionnaire consisted of demographics: gender, age, educational level, occupation and residence; whereas the second questionnaire consists of several dimensions such as: access of doctors to the primary system in Pristina, issuance of a prescription for antibiotic use in this municipality, issuance of antibiotic prescription in uncontrolled quantities, patient information about antibiotic use, all inclusive in health care and overall. Participants' answers are evaluated with agree (1), neutral (2) and disagree.

\section{Results}

Of the 120 doctors (surveyed) respondents at PHC, on the question: do you have antibiotics that you are familiar with, more than half (55\%) do not have any favorite antibiotics, and $40 \%$ of them have some antibiotics with whom they are familiar.

\footnotetext{
1 The Ministry of Health of Kosovo, "The Sectorial Strategy of Health Care in Kosovo 2015-2020" (2018)

2 CDC Report "Antibiotics Resistance Threats in the USA" (2013)

${ }^{3}$ C. Lee Ventola "The Antibiotic Resistance Crisis" (2015)

4 The Ministry of Health of Kosovo, "The Sectorial Strategy of Health Care in Kosovo 2015-2020" (2018)

5 Jakupi A. Report: Drug consumption in Kosovo 2011-2013. Kosovo Medicines Agency - Pristina, 2014.
} 
Although $8.1 \%$ of family doctors have reported that they are familiar with many of the antibiotics, there has been no significant difference after the testing

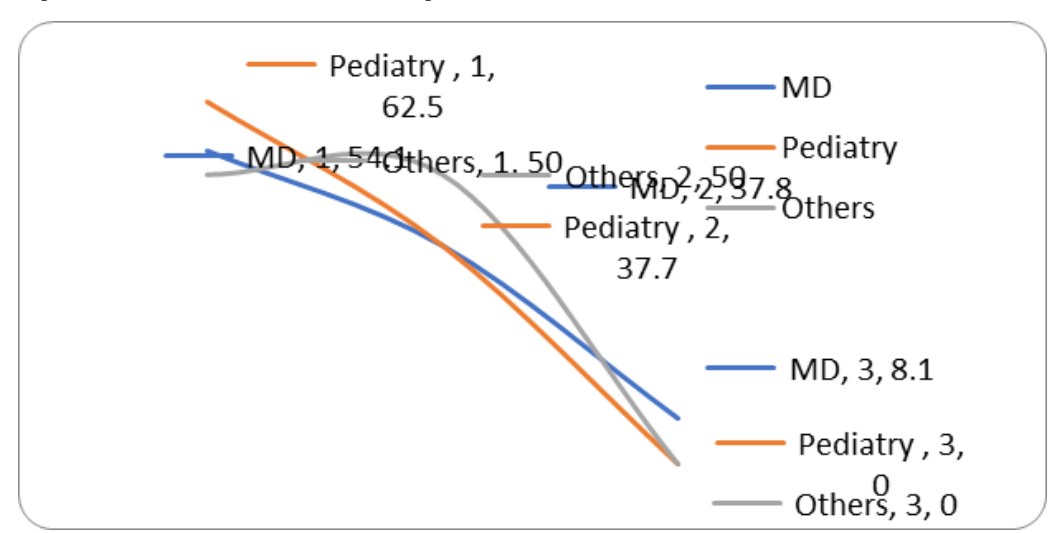

(Chi-square $=4.76 ; \mathrm{Df}=4 ; \mathrm{p}=0.313)$. (Table 1)

Only $10.8 \%$ of the surveyed doctors do not prescribe antibiotics without antibiogram. After testing with chi square test we did not gain significant difference in the description of antibiotics without antibiotics according to specialization branches.

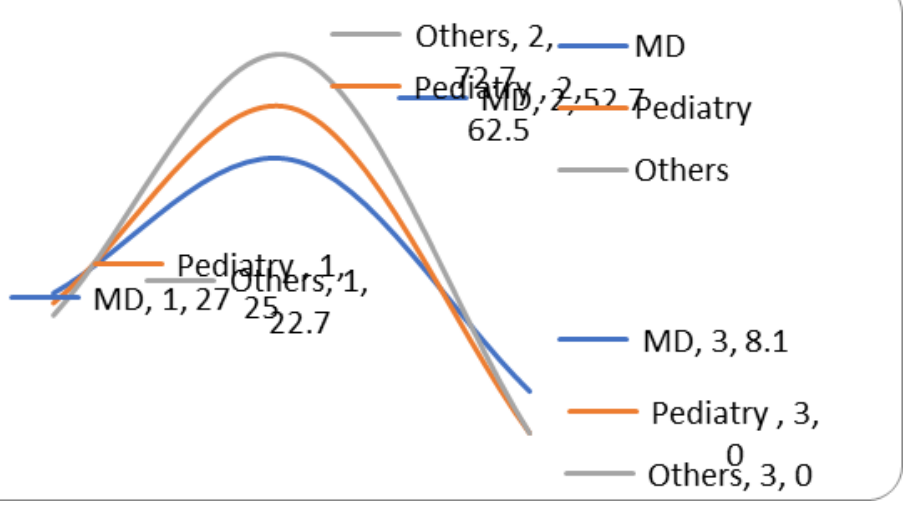

(Chi-square $=6.10 ; \mathrm{Df}=6 ; \mathrm{p}=0.412$ ). (Table 2)

Respondents were asked whether they give patients advice on side effects. After analyzing data, 72 doctors or $60.0 \%$ always give advice to their patients for side effects, 29 or $24.2 \%$ frequently and 14 or $11.7 \%$ occasionally, while 5 doctors or $4.2 \%$ do not give advice to their patients for the effects side. After testing with chi square test we have not gained significant difference in providing advice to the patients for side effects by specialty branches. 


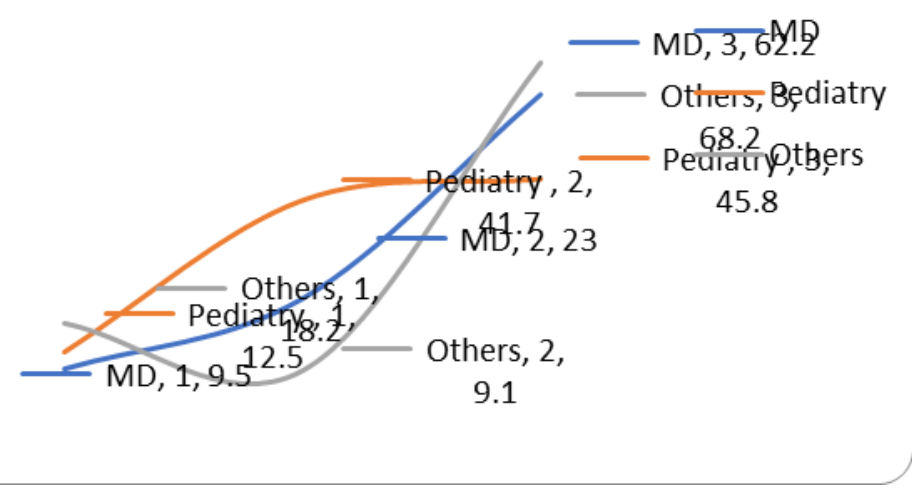

(Chi-square $=8.66 ; \mathrm{Df}=6 ; \mathrm{p}=0.193)$. (Table 3)

Respondents were also asked whether they have scientific evidence of which antibiotics think it is producing antimicrobial resistance and after analyzing respondents' responses that only half of 62 or $51.7 \%$ have some scientific evidence a large proportion of doctors 48 or $40 \%$ have no scientific evidence for any antibiotic that creates antimicrobial resistance and only 10 doctors and 4 pediatricians have enough evidence of which antibiotics create antimicrobial resistance.

According to the specialists 'branches and respondents' responses we did not make a significant difference although in a few percent and only 10 doctors and 4 pediatricians have sufficient evidence of which of the antibiotics creates antimicrobial resistance high (16.7\%) Pediater physicians have said they have enough evidence of antimicrobial resistance to some antibiotics.

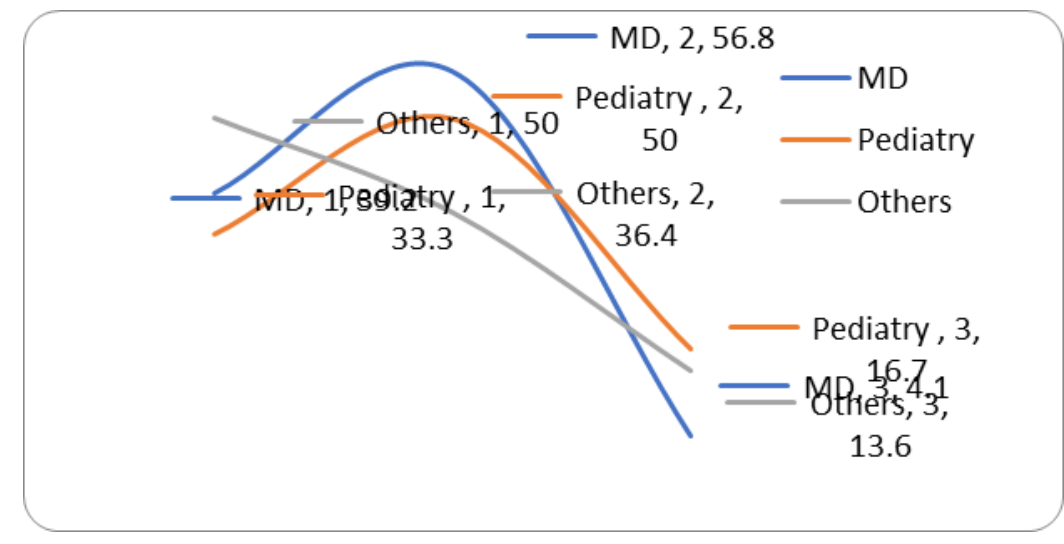

(Chi-square $=6.58 ; \mathrm{Df}=4 ; \mathrm{p}=0.160)$. (Table 4)

Respondents were asked that in their daily practice "Do they describe antibiotics in cases of flu-like patients" and after analyzing the data it is seen that the majority of doctors 96 or $80 \%$ stated that they did not describe only 5 doctors or $4.2 \%$ stated that they prescribed it and that is mainly family doctors. After testing with chi square test we did not gain significant difference in respondents' responses to whether they describe antibiotics inpatients with grip condition in their daily work according to their occupations. 


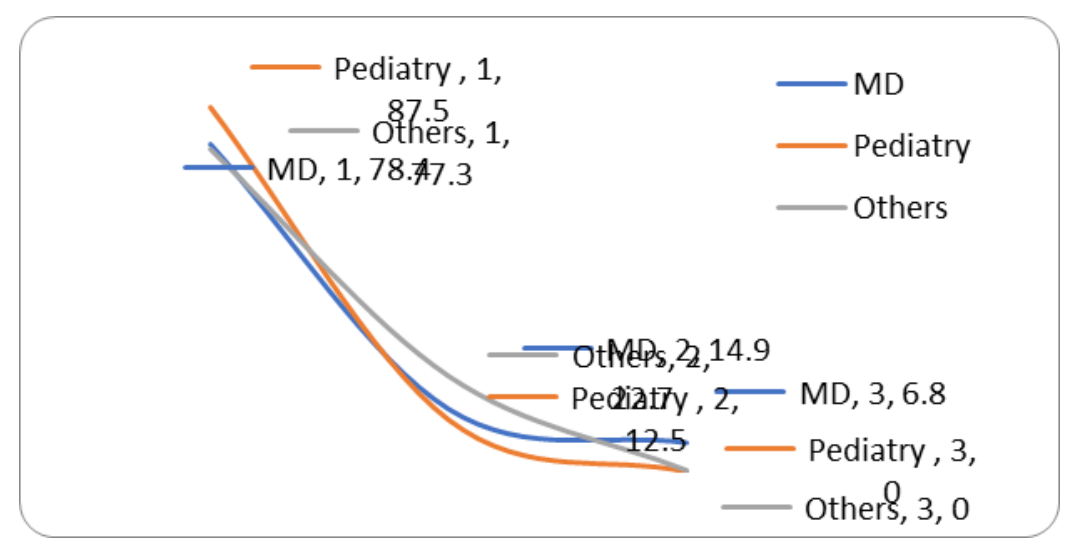

(Chi square test $=4.19 ; \mathrm{Df}=4 ; p=0.380)$. (Table 5$)$

Also very important aspect presents even rational description not rational of drugs and antibiotics in healthcare institutions so doctors surveyed were asked that "Is there a rational use of antibiotics in their institution", based on the results, only 66 or $55.0 \%$ of the respondents stated that they have some, 39 or $32.5 \%$ declare that there is no rational use of antibiotics while 15 or $12.5 \%$ declare that in their institutions there is unreasonable use of antibiotics. According to specialist branches, pediatricians at a slightly higher percentage $(70.8 \%)$ stated that they had "to some extent" unbiased use of antibiotics, but without significant difference.

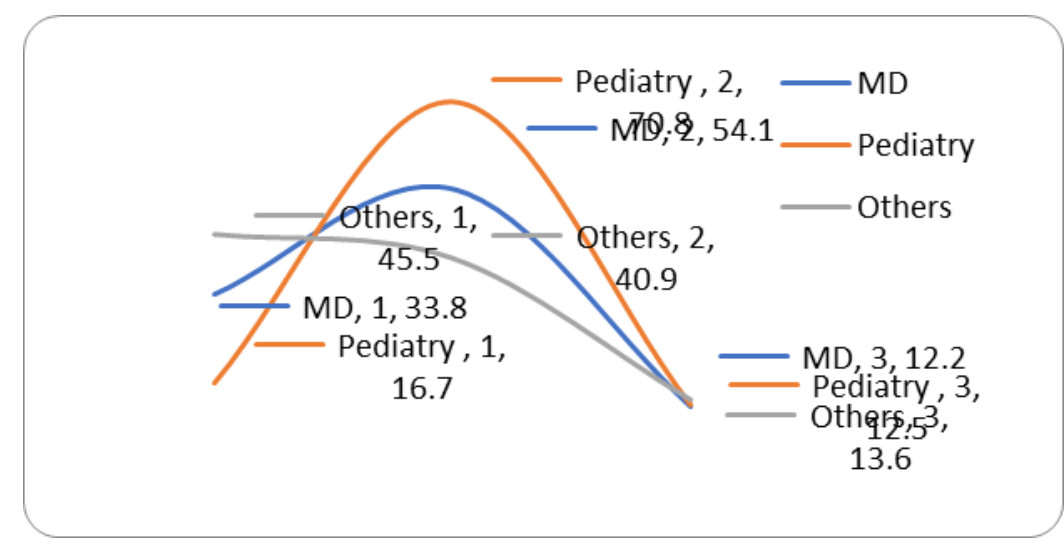

(Chi-square $=4.95 ; \mathrm{Df}=4 ; \mathrm{p}=0.292$ ). (Table 6)

Respondents were asked that: "Do you think the over-use of antibiotics affects the loss of their effects", and based on the results it appears that doctors are aware that over-use of antibiotics affects the loss of their effects and 92 or $76.7 \%$ know, 18 or $15.0 \%$ think up to one factor, while 10 doctors or $8.3 \%$ do not have much knowledge and declare that it does not affect, according to specializations other specialties at a slightly higher percentage $81.8 \%$ know that over-consumption affects the reduction of side effects but without significant difference according to the specialization branches. 


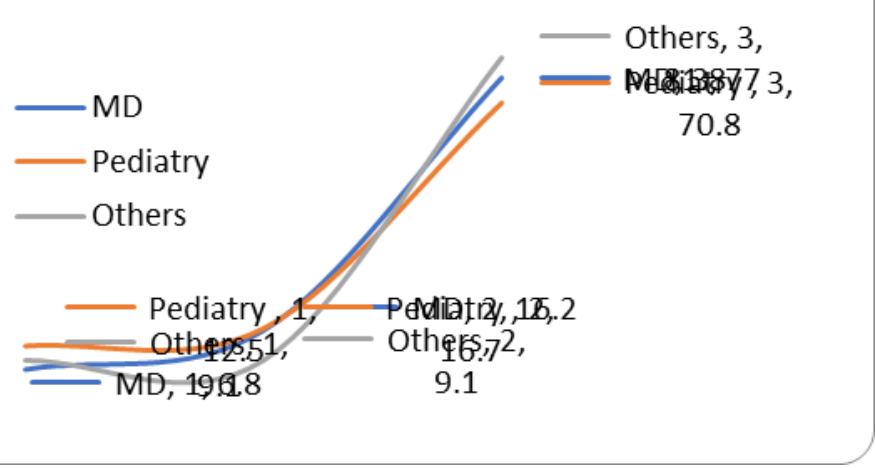

(Chi-square $=1.55 ; \mathrm{Df}=4 ; \mathrm{p}=0.818)$. (Table 7)

As far as antibiotic supplies are concerned, the institutions where the doctors work, only 73 or $60.8 \%$ stated that their instincts were somewhat supplied, 36 . or $30.0 \%$ stated that the institutions where they work are not supplied while only 11 doctors or $9.2 \%$ declare that their institutions are well supplied with antibiotics.

After testing the respondents' responses, significant difference was obtained for $P<0.001$ for the supply of institutions Pediatricians have stated that they are not supplied, and that is 13 or $54.2 \%$ with significant difference according to specialist branches while MF (62.2\%) and doctors of other branches $(72.7 \%)$ stated that they are supplied with antibiotics

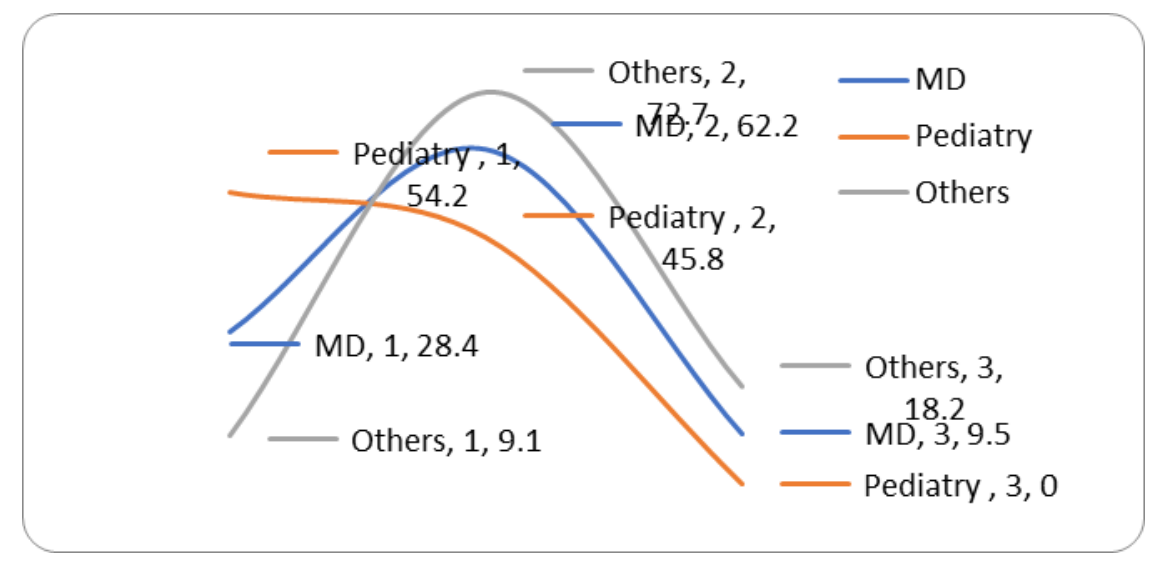

(Chi-square $=13.5 ; \mathrm{Df}=4 ; \mathrm{p}=0.009)$. (Table 8)

Also doctors surveyed were asked how many hours a week they work to know that schedule does have an impact on the description of antibiotics and most of them work 40 hours and a low percentage of them work with few hours or prolonged hours 8 cases or $6.7 \%$. After testing the results there is no significant difference according to the specialization branches. 


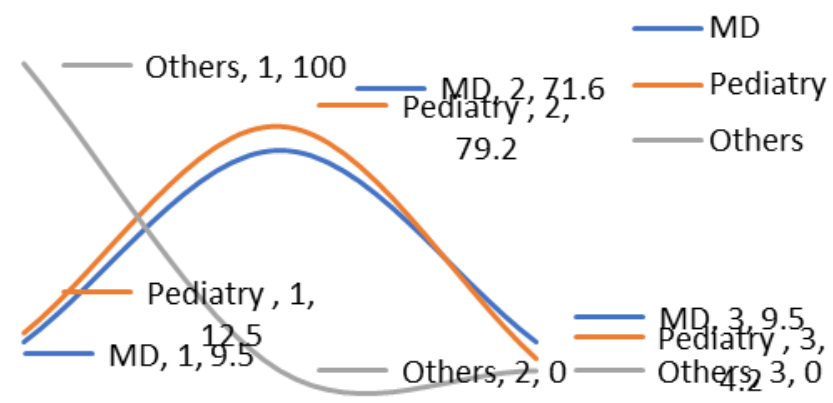

(Chi-square $=9.31 ; \mathrm{Df}=6 ; \mathrm{p}=0.157) .($ Table 9)

\section{Discussion}

Out of a total of 120 doctors surveyed at PHC, no significant difference has been found in interviewed staff on the question of whether they have antibiotics with whom they are familiar and access and preference to antibiotics is the same regardless of the type of specialization of staff at PHC. About one-fourth of respondents describe antibiotics without antibiograms, and over half of them sometimes and only $10.8 \%$ do not prescribe antibiotics without antibiograms, regardless of the type of specialization of staff at PHC. Providing advice to the patients on side effects is accomplished by most doctors of PHC and only 5 doctors or $4.2 \%$ do not give advice to their patients for side effects, but without significant difference depending on the type of specialization. Over $80 \%$ of respondents in their daily practice have encountered a known case of resistance to an antibiotic, but without distinction depending on the type of specialization.

Respondents were asked whether they have scientific evidence of which antibiotics think they produce antimicrobial resistance and 48 or $40 \%$ stated that they have no scientific evidence for any antibiotic that creates antimicrobial resistance but according to respondents' specialization and response branches we have gained significant difference although in slightly higher percentages (16.7\%) Pediater physicians have said they have sufficient evidence for antimicrobial resistance to some antibiotics. The majority of doctors, 96 or $80 \%$, stated that they did not describe their daily antibiotic practice in cases of flu-like patients, regardless of their occupational significance. About one-third of respondents stated that there is no rational use of antibiotics, according to specialty branches. Pediatricians at a slightly higher percentage $(70.8 \%)$ stated that there was "to some extent" non-rational use of antibiotics but without distinction significant.

It is apparent that doctors are aware that over-use of antibiotics affects the loss of their effects and that $92 \%$ or $76.7 \%$ know, while 10 doctors or $8.3 \%$ do not have much knowledge and have stated that it does not affect, according to specializations other specializations in a few percent higher $81.8 \%$ know that overconsumption affects the reduction of side effects but without significant difference according to the specialization branches. The supply of antibiotics to the institutions where the doctors are working is in line with 73 respondents or $60.8 \%$ whereas $36 \%$ or $30.0 \%$ stated that the institutions where they work are not supplied. Significant difference has been made in terms of supplying institutions where antibiotics work. Pediatricians have stated that they are not supplied and that $13 \%$ or $54.2 \%$ with significant difference according to specialty branches while MF (62.2\%) and doctors of other branches (72.7\%) stated that they are supplied with antibiotics. It can be concluded that significant difference has been identified among interviewed personnel regarding the supply of antibiotics to the institutions where they work and Pediatric Doctors have stated that they are not supplied with antibiotics or other antibiotics outside the essential list. The vast majority of staff work 40 hours and no significant difference has been observed according to the specialty branches in the description of antibiotics.

\section{Conclusion}

This study revealed an advanced level of the knowledge of doctors' practices in Prishtina health centers. The doctors are the ones who contribute in the use of antibiotics for Pristina's population. The key findings of this study will help policymakers 
in Kosovo to develop new strategies to improve health care at the primary level. To accomplish this, the following measures should be considered: (a) Drafting medical protocols; (b) use the evidence-based guidelines and protocols for issuing prescriptions for antibiotic use; (c) organize seminars in the Primary Health Centers regarding the usage of antibiotics in order to provide doctors and support staff with the latest news on the consequences and effects of antibiotics to the human body; (d) monitor the implementation of medical guidelines according to European standards; (e) use social media for informing and promoting the rational use of antibiotics.

\section{References}

[1] Adriaenssens N, Coenen S, Versporten A, Muller A, Minalu G, Faes C, Vankerckhoven V, Aerts M, Hens N, Molenberghs G, Goossens H ESAC Project Group. European Surveillance of Antimicrobial Consumption (ESAC): outpatient antibiotic use in Europe (1997-2009) J Antimicrob Chemother. 2011;66 (Suppl 6):vi3-vi12.doi: 10.1093/jac/dkr453. [PubMed]

[2] Bronzwaer SL, Cars O, Buchholz U, Mölstad S, Goettsch W, Veldhuijzen IK, Kool JL, Sprenger MJ, Degener JE European Antimicrobial Resistance Surveillance System. A European study on the relationship between antimicrobial use and antimicrobial resistance. Emerg Infect Dis. 2002;8(3):278-282. [PMC free article] [PubMed]

[3] Goossens H. Antibiotic consumption and link to resistance. Clin Microbiol Infect. 2009;15(Suppl 3):12-15.doi: 10.1111/j.14690691.2009.02725.x. [PubMed]

[4] Goossens, \& Herman. (2014). Antibiotic use in eastern Europe: a cross-national database study in coordination with WHO Regional office for Europe the lancet infections disease.

[5] Gustafson B. S., and Ziv (1986). Insulin resistance and impaired adipogenesis.

[6] Goossens H. Antibiotic consumption and link to resistance. Clin Microbiol Infect. 2009;15(Suppl 3):12-15.doi: 10.1111/j.14690691.2009.02725.x. [PubMed]

[7] Jeffrey, A. L. (2013). Divizion of general medicine and primary care of BWH.

[8] Jeffrey, A. L. (2013). Wikimedia Commons.

[9] Jeffrey K. Zeig, Stephen G. Gilligan (2013). Brief Therapy: Myths, Methods, and Metaphors

[10] Jakupi A. Report: Drug consumption in Kosovo 2011-2013. Kosovo Medicines Agency - Pristina, 2014.

[11] Keci A. (2015). Farmakologjia

[12] Laxminarayan R, Duse A, Wattal C, Zaidi AK, Wertheim HF, Sumpradit N, Vlieghe E, Hara GL, Gould IM, Goossens H, Greko C, So AD, Bigdeli M, Tomson G, Woodhouse W, Ombaka E, Peralta AQ, Qamar FN, Mir F, Kariuki S, Bhutta ZA, Coates A, Bergstrom R, Wright GD, Brown ED, Cars 0 . Antibiotic resistance - the need for global solutions. Lancet Infect Dis. 2013;13(12):1057-1098. doi: 10.1016/S1473-3099(13)70318-9.[PubMed]

[13] Lory, J.Schroth, (2011). Brigham and women's hospital communication's use and abuse antibiotics colle agues for excellence., American Association of Endodontists.

[14] Maragakis LL, Perencevich EN, Cosgrove SE. Clinical and economic burden of antimicrobial resistance.Expert Rev Anti Infect Ther. 2008;6 (5):751-763. doi: 10.1586/14787210.6.5.751. [PubMed]

[15] Mandro, F., Zahaj, M., Xhoja, A., \& Hxhija, L. (2013).Neuhauser, M. M., Weinstein, R,A., Rydman, R., Dansinger, L,H., Karam \& Quinn, N,N. (2003). Antibiotic rezistence among gram-negativ bacilli in US intensive care units: implications for Fluoroguine lone USE. Jama.

[16] McNulty CA, Boyle P, Nichols T, Clappison P, Davey P. The public's attitudes to and compliance with antibiotics. J Antimicrob Chemother. 2007;60(Suppl 1):i63-i68. [PubMed]

[17] Tom Frieden, M. M. (2013). Meeting the Challenges of Drug-Resistant Diseases in Developing Countries. United States House of Representatives.

[18] Finkelstein, J. A., Matlay, J. P., Davis, R. L., Rifas-Shiman, S. L., Doëel, S. F., \& Platt, R. (2000). Antimicrobial use in defined populations of infants and young children. Arch pediatr adolesc med, 154(4):395-400. Pub Med

[19] Preheve, J. C. (2011). Infectious Diseases Society of America.

[20] Raka, L. (2011). Strategjjja dhe plani i veprimit për rezistencën antimikrobike. Prishtinë.

[21] Raka, L., Azizi, E., \& Berisha, F. (2011). Rezistenca ndaj antibiotikëve në kosovë. Prishtinë.

[22] Ramanam, Laxninarayan, \& Backel, T. V. (2014). The lancet of infections disease.

[23] Sabuncu, E., David J., Bernede - Bauduin, C \& et al. (2009). Significant reducioin antibiotic use in the community after a nationëide conpiagnin France.

[24] WHO (2002). World Health Report of Geneva. 